\title{
Ancoradas no corpo, ancoradas na experiência: etnografia, autoetnografia e estudos em dança
}

Anchored in the body, anchored in the experience: ethnography, autoethnography and dance studies

Mônica Fagundes Dantas ${ }^{1}$ 


\section{Resumo}

O crescimento e a consolidação de Cursos de Pós-Graduação em Artes Cênicas no Brasil tem alavancado discussões sobre abordagens e procedimentos metodológicos voltados para as pesquisa em artes cênicas. Este artigo tem por propósito refletir sobre a contribuição e os limites - da etnografia e da autoetnografia para pesquisa em dança. Situa a etnografia e a autoetnografia, traçando relações com estudos no campo da dança e apresenta alguns estudos que, servindo-se de uma abordagem etnográfica ou auto-etnográfica, ancoram-se radicalmente no corpo.

Palavras-chave: Pesquisa em artes cênicas; dança; Etnografia; auto-etnografia; Corpo.

\section{Abstract}

The growth of Postgraduate Programs in Performing Arts in Brazil has been motivating discussions on methodological approaches for the development ot this field. This article aims to reflect on the contribution - and the limits - of ethnography and autoetnografia for research in dance. It situates ethnography and autoetnografia and make relations with the dance field. Finally, it presents some studies, radically anchored in the body, that uses an ethnographic or self-ethnographical approach.

Keywords: Research in performing art; dance; ethnography; authoetnography; body. 


\section{Introdução}

O crescimento e a consolidação de Cursos de Pós-Graduação em Artes Cênicas (Telles, 2012; Fernandes, 2015) no Brasil tem alavancado discussões sobre abordagens e procedimentos metodológicos voltados para as pesquisa em artes cênicas (Telles, 2012; Dantas 2007; Fortin e Gosselin, 2015; Fernandes 2015; Pinto, 2015; Castro, 2015).

Há uma tendência a se diferenciar a pesquisa sobre arte da pesquisa em arte (Conte, 2000; Lancri, 2002; Fortin 2006). A pesquisa sobre arte aporta um ponto de vista exterior sobre as obras de arte, os processos artísticos, as condições de recepção da obra, as relações sociais e econômicas que permeiam a produção e a recepção das obras. A pesquisa em arte se situa no contexto de uma prática pessoal, é conduzida e realizada pelo artista a partir do processo de instauração da obra, articulando num mesmo processo a produção de uma obra ou situação artística e uma forma de saber sobre esta produção que interage com a obra.

Fortin (2006) ressalta ainda uma terceira categoria, a pesquisa de prática artística. Semelhante à pesquisa em arte, é uma investigação que se realiza em terrenos de prática artística (ateliês, salas de ensaio, teatros, espaços de interação entre artistas e público), buscando explicitar os saberes operacionais implícitos à produção de uma obra ou situação artística. No entanto, a pesquisa de prática artística nem sempre é realizada pelo próprio criador da obra ou situação artística, podendo ser realizada por um outro artista que se coloca como pesquisador. Nesse sentido, Fortin (2006) explica que quando um artista procede a uma investigação sobre a prática de outro artista, ele o faz a partir de um ponto de vista de artista e isso influencia as diversas etapas da sua pesquisa. Desse ponto de vista, a pesquisa de prática artística engloba a pesquisa em arte. Proponho, em diálogo com essa perspectiva, pensar numa pesquisa em prática coreográfica: aquela que explicita os saberes operacionais que são implícitos ao fazer coreográfico e associa, num mesmo processo, a produção de uma obra ou evento coreográfica a uma forma de saber sobre esta produção que interage com a obra ou evento.

A partir da minha experiência como pesquisadora e artista de dança, este artigo tem por propósito refletir sobre a contribuição - e os limites - da etnografia e da autoetnografia para pesquisa em prática artística no âmbito dos estudos em dança.

\section{A etnografia como abordagem metodológica}

Numa definição já clássica, a etnografia é um método de pesquisa que considera a dimensão sociocultural do fenômeno estudado, caracterizando-se como uma atividade minuciosa e reflexiva de observação e descrição, a partir da imersão do pesquisador no seu campo de trabalho (Patton, 2002). O investigador fica comprometido como instrumento, objeto e sujeito da investigação, na medida em que progride sua imersão no campo. Laplantine (2000) ressalta que o objetivo principal da etnografia é a aprendizagem por impregnação de "[...] uma cultura que não é a minha 
ou de um segmento de minha própria cultura" 2(p.7). Para o autor, etnografia e antropologia são indissociáveis, pois é a partir da descrição etnográfica que se elabora o conhecimento específico da antropologia.

A etnografia percorreu um caminho indo do estudo das culturas exóticas ao estudo de culturas locais e de grupos sociais minoritários e marginalizados. A partir dos anos 1980, o conceito de etnografia foi questionado e revigorado em seu próprio território, a antropologia. A crítica da prática etnográfica tradicional expôs os limites das práticas de representação, o que levou os pesquisadores a questionarem suas relações com os sujeitos e grupos estudados e a propor novos modos reflexivos e autorreflexivos de produção de conhecimento (Marcus e Fisher, 1986).

Mais recentemente, a etnografia passou a se interessar pelo estudo das estruturas de poder nas sociedades complexas. Marcus (2002) se refere a etnografias que se dedicam a compreender o Estado constitucional, as ciências, o sistema das artes, as mídias, as corporações econômica, o sistema político. O autor também aborda a etnografia multi-site ou multisituada, a qual não define para si um objeto de estudo que não pode ser abordado etnograficamente se permanece centrado em uma só localidade intensamente investigada. Trata-se de uma etnografia móvel, que, muitas vezes, escolhe temas de ordem social, econômica e política típica das sociedades complexas, a fim de penetrar nos mundos vividos de certos sujeitos, sejam eles dominados ou dominantes.

Como assinala Frosch (1999), a investigação etnográfica transpôs as fronteiras da antropologia e é cada vez mais utilizada em áreas como a educação, a literatura comparada, os estudos de gênero, os estudos culturais, a saúde pública, as artes, a dança, entre outras. A autora refere-se à necessidade de distinguir a etnografia da antropologia, pois a etnografia não é mais definida por linhagens disciplinares ou por perspectivas teóricas, mas por uma abordagem descritiva que permite ao pesquisador se reconhecer no ponto de vista dos sujeitos que participam da pesquisa.

Fortin (2006) estabelece uma distinção entre a pesquisa tipicamente etnográfica e a pesquisa de caráter etnográfico. Ressalta que a maior parte das pesquisas em prática artística apresenta um caráter etnográfico, pois pressupõe um trabalho de observação e descrição de comportamentos humanos, privilegiando o ponto de vista dos participantes. Tais pesquisas se apoiam em dados etnográficos, a saber, dados empíricos que resultam da presença do pesquisador no terreno de prática, mas eles não correspondem, necessariamente, a problemáticas de ordem cultural ou social.

\section{A etnografia e os estudos em dança}

A etnografia tem sido utilizada em diferentes perspectivas de pesquisa em dança. Como destaca Frosch (1999), a etnografia em dança emergiu como uma referência importante para o estudo da dança numa perspectiva cultural, tendo sido utilizada por antropólogos, mas também por outros pesquisadores em dança. Sklar (1991) destaca o caráter particular da pesquisa etnográfica em dança, pois a etnografia da dança é única entre outros tipos de etnografia porque é necessariamente ancorada

2 Tradução livre minha: « [...] d'une culture qui n'est pas la mienne ou d'un segment de ma propre culture... » (Laplantine, 2000, p.7) 
no corpo e na experiência do corpo, ao invés de basear-se em textos, artefatos ou abstrações.

Se atualmente pode-se referir às possibilidades de cruzamento entre a dança e a etnografia com tranquilidade, as relações entre a etnografia, a antropologia e os estudos em dança não foram sempre tão evidentes. Davida (2001) mostra que só recentemente certos pesquisadores em dança, provenientes de áreas como a filosofia, a estética e a história da arte, começaram a se interessar por uma abordagem antropológica das danças artísticas de tradição ocidental, como o balé e a dança moderna. Os antropólogos que se dedicavam à dança também eram reticentes quanto ao estudo das formas de danças oriundas de tradições ditas eruditas. Assim, até meados dos anos 1980, a maior parte dos estudos etnográficos em dança era centrada nas sociedades e suas danças ditas tradicionais ou populares. Assim, autores como Grau (1998), Kaeppler (1985) e Kealiinohomoku (1976) utilizaram a etnografia como método de pesquisa para elaborar conhecimentos na perspectiva da antropologia. Ou seja, estudam-se as danças para melhor compreender as sociedades. Para outros pesquisadores, o estudo do contexto social serve principalmente para aprofundar a compreensão das danças. É o caso dos estudos em folclore e em etnologia da dança (Andrade, 1959; Bakka, 1999; Felföldi, 1999; Giurchescu, 1999; Koutsuba, 1999).

Em um dos textos fundadores da antropologia da dança ${ }^{3}$, Kealiinohomoku (1998) sublinha a falta de conhecimento que os especialistas da dança artística ocidental demonstram quando escrevem sobre as danças tradicionais. A autora reivindica um olhar que relativize as formas de dança ditas tradicionais e artísticas e demonstra que o balé pode ser concebido como uma forma de dança étnica. Na verdade, segundo Kealiinohomoku (1998), toda dança é étnica, pois toda dança é um reflexo das tradições culturais nas quais ela se desenvolveu. O que Davida (2001) chama de legado de Kealiinohomoku, ou seja, a realização de etnografias sobre as formas de dança provenientes de tradições artísticas ocidentais, só se concretiza com a publicação de Sharing the Dance, Contact Improvisation and American Culture, de Cynthia Novack, em 1990. Neste estudo, a autora adota uma perspectiva etnográfica para compreender o improvisação por contato como parte da cultura estadunidense. Novack concebe a improvisação por contato como um movimento artístico e social e, ao longo de sua obra, analisa o caráter artístico da dança em relação com os aspectos sociais e culturais. Desse modo, o estudo dessa forma de dança ilumina o contexto cultural, ao mesmo tempo em que o estudo do contexto permite uma melhor compreensão da dança.

Nos anos 1990 intensifica-se a produção de estudos etnográficos sobre danças praticadas nos centros urbanos. Em geral, essas pesquisas se debruçam sobre a prática de certos estilos de danças populares realizadas por grupos específicos. É o caso dos estudos de Browning (1995) e Gore (1998). Alguns, como o trabalho de Gore (1998), examina dança a fim de compreender a cultura rave, estão mais próximos da antropologia. Outras investigações utilizam a etnografia para aprofundar a compreensão da própria dança, como acontece com Browning (1995), que utiliza a

3 Este artigo foi publicado pela primeira vez em 1970. Em 1998 foi publicada uma versão em francês, utilizada na redação deste texto. Em 2013 foi publicada sua versão em português (Kealinohomoku citada por Camargo, 2013). 
etnografia para enfatizar aspectos técnicos, poéticos e simbólicos de certas danças brasileiras, como o samba, a capoeira, as danças presentes nas religiões afro-brasileiras e o carnaval de Salvador.

Do mesmo modo, desde o fim dos anos 1980, diversos estudos etnográficos têm sido realizados no âmbito do ensino da dança, tais como Blumenfeld-Jones (1995), Fortin (1994, 1999), Fortin e Long (2005), Green (1996) e Stinson (1993). Uma parte significativa dessas pesquisas trata do ensino da dança moderna e contemporânea e aborda temas diversos, como os significados da dança para os seus praticantes, a integração de práticas de educação somática ao ensino da dança contemporânea, as relações de poder estabelecidas entre professores e alunos nas aulas de dança, etc. Tais estudos estão muito próximos à etnografia educativa, cujo objetivo é oferecer dados descritivos sobre os contextos, atividades e os modos de pensar daqueles que fazem parte de ambientes educativos. Além disso, esses estudos servem como referência às pesquisas etnográficas centradas na criação e interpretação de coreografias.

Coexistem atualmente diferentes tipos de estudos etnográficos sobre a dança, que perseguem objetivos diferentes e utilizam quadros teóricos distintos. Nota-se, recentemente, um incremento na produção de etnografias sobre as ditas formas de danças cênicas ocidentais, seja no âmbito do balé ou da dança contemporânea. Wulff (1998) descreve o balé como uma prática transnacional, a partir de uma análise da carreira de bailarinos e dos processos de produção dos espetáculos de balé em companhias de diferentes países. Os trabalhos de Turner e Wainwright (2003) debruçamse sobre os casos de bailarinos clássicos lesionados ou aposentados ou em vias de se aposentarem, questionando a vulnerabilidade e a identidade desses bailarinos.

No caso da dança moderna e contemporânea a utilização da etnografia também serve a fins diversos. Santos (1999) identifica os elementos culturais que se manifestam nas coreografias de certas companhias de dança contemporânea da cidade de Vitória, procurando compreender como esses elementos podem constituir-se em expressões da cultura brasileira. Davida (2006) conduziu seu estudo com uma companhia de Montreal, no Canadá, para compreender as múltiplas significações que uma produção de uma obra coreográfica pode ter para bailarinos, coreógrafos, técnicos, membros da administração da companhia, produtores, difusores culturais, público. Thomas (2003) acompanhou a reconstrução, em 1977, de uma coreografia de Doris Humphrey (Water Study), de 1928, a fim de refletir sobre os procedimentos de recriação e manutenção de repertórios de dança numa relação com a noção de autenticidade, tão cara à dança moderna.

A etnografia, como já foi dito, tem sido utilizada para embasar as pesquisas em prática artística, em particular, em prática coreográfica. Muitos artistas que desenvolvem pesquisas na universidade o fazem problematizando sua própria criação. Como aponta Fortin (2006), nesses casos, a autoentnografia pode apoiar as reflexões sobre processos de criação coreográfica. A autoetnografia vem se consolidando como uma escrita de si, que permite o ir e vir entre as experiências pessoais e as dimensões culturais, buscando reconhecer, questionar e interpretar as próprias estruturas e políticas do eu. Uma parte significativa dos artistas/pesquisadores procede a colheita de informações sobre sua própria trajetória e processo de criação, procedimento que 
se assemelha a uma colheita de dados autoetnográficos. Nesse caso, o pesquisador utiliza essas informações para produzir conhecimentos intrínsecos à prática artística. Em geral, o produto dessas pesquisas é um texto escrito, que dialoga com a obra coreográfica.

Os dados etnográficos podem também ser utilizados para alimentar diferentes etapas da criação coreográfica. Nesse caso, o produto da pesquisa é a própria coreografia, como no caso de Graziela Rodrigues. Para a criação de Graça Bailarina de Jesus (1980), ela fez um trabalho de campo nos terreiros de umbanda da periferia de Brasília, onde participou dos rituais religiosos, aprendendo os cantos e as danças sagradas. Num segundo momento, ela trabalhou em estúdio, em colaboração com um diretor teatral, para finalizar a coreografia e dar corpo à obra (Rodrigues, 1987). Inspirada por esta experiência, continuou os estudos etnográficos sobre as danças populares brasileiras e desenvolveu método de formação do bailarino-pesquisador -intérprete (B.P.I.), publicado em 1997. A partir do estudo de certas danças populares brasileiras, mais especificamente das danças presentes nos religiões afro-brasileiras, Rodrigues (1997) extraiu os princípios técnicos e simbólicos que estruturam seu método de preparação corporal e de criação coreográfica. A última etapa desta proposição consiste na colheita de dados etnográficos num contexto de uma manifestação popular brasileira, no qual o bailarino-pesquisador-intérprete recolhe material para sua criação coreográfica. Rodrigues (1997) destaca que, durante todo o processo, o bailarino se serve do seu corpo como um dos principais instrumentos do seu trabalho de campo. O Método B.P.I consolidou-se como metodologia de formação e criação cênica a partir, principalmente, da atuação de Graziela Rodrigues na Graduação em Dança e na Pós-Graduação em Artes da Cena da Universidade de Campinas (Campos; Rodrigues, 2015).

Do mesmo modo, autores como Fortin (1994) e Frosch (1999) referem-se à empatia cinestésica como um componente importante da pesquisa em dança. A possibilidade de utilização da informação cinestésica como dado etnográfico está relacionada com as vivências corporais do pesquisador. Merleau-Ponty (1971) menciona a interseção entre os sentidos e a correspondência entre a visão, o tato e o movimento: "os sentidos se traduzem um ao outro sem terem necessidade de um intérprete, se compreendem um ao outro sem terem de passar pela idéia" (p. 241). Do mesmo modo, Frosch (1999) sublinha que a experiência fenomenológica do pesquisador durante o trabalho de campo é facilitada pela empatia cinestésica, uma qualidade altamente desenvolvida pelos dançarinos. A aprendizagem da dança e, em particular, da dança contemporânea, se faz através da interseção entre o olhar, o ouvir, o sentir e o mover-se. Fortin (1994) destaca que a pesquisa em dança interpela a corporeidade do pesquisador, pois ele deve integrar em sua pesquisa o corpo em movimento.

Lepecki (1998) também propõe aproximações entre a etnografia e a prática coreográfica. O artista etnógrafo, noção proposta por Hal Foster (citado por Lepecki, 1988), é aquele que desloca o eixo de composição e criação do agenciamento dos meios e materiais de que dispõe em direção a uma intervenção em seu ambiente cultural e sociopolítico. Servindo-se desse conceito, Lepecki (1998) explica que uma parte dos coreógrafos contemporâneos ditos experimentais - que ele denomina 
como vanguarda posbauschiana ${ }^{4}$ - utiliza um método etnográfico de composição coreográfica. Esse método, como a etnografia, é baseado na observação da ação e do comportamento dos bailarinos, na formulação de questões sobre temas sociológicos, na seleção do material e, para finalizar, na colagem dos dados que organiza a forma final da obra coreográfica.

Se essas práticas coreográficas se aproximam do método etnográfico, a etnografia contemporânea se aproxima também das práticas artísticas, propondo transformações no texto etnográfico. Essa escrita etnográfica utiliza procedimentos como a justaposição, a manipulação e a colagem inabitual de objetos, de sons, de imagens e de movimentos, para restabelecer os sentidos da experiência de campo. E não é essa também a busca de artistas da dança? Restabelecer o sentido das experiências de criação, quando elas são oferecidas ao público?

\section{Ancorada no corpo, ancorada na experiência}

Caracterizo minhas investigações dos últimos 15 anos como pesquisas de prática coreográfica, pois nelas proponho problemáticas artísticas e um trabalho de coleta e produção de dados e informações realizado em terrenos de prática coreográfica. Essas pesquisas dialogam com uma abordagem fenomenológica do corpo. Nos meus estudos de mestrado (Dantas, 1999), para compreender o corpo dançante como sensível e disponível, utilizei as noções de corpo vivido, corpo fenomenal e corpo próprio, elaboradas por Merleau-Ponty (1971). Na pesquisa realizada para a elaboração de minha tese de doutorado (Dantas, 2008), onde aprofundo meus estudos sobre processos de criação coreográfica e formação de bailarinos no contexto da dança contemporânea no Brasil, continuei a utilizar o aporte da fenomenologia para tratar do corpo dançante. Mas ao invés de privilegiar uma abordagem eminentemente teórica desses temas, tive vontade de confrontar certos conceitos com a experiência de outros bailarinos e coreógrafos que vêm construindo a dança contemporânea no Brasil. Assim, buscando dados empíricos e respaldada pela trajetória de outros pesquisadores (Davida, 2006; Fortin, 2006; Frosch, 1999; Santos, 1999) utilizei a etnografia como a principal referência metodológica. Fui então instigada a refletir sobre as relações entre etnografia e fenomenologia.

Nas minhas pesquisas (Dantas, 2005, 2007, 2008) recorro então à fenomenologia e à etnografia para continuar a refletir sobre o corpo dançante e o fazer coreográfico. Autores como Csordas (1994), Laplantine (2000) e Thomas (2003) sublinham as relações entre as duas disciplinas. Csordas $(1993,1994)$ elabora seu pensamento no cruzamento entre a fenomenologia e a antropologia, o que o conduz à noção de corporeidade (embodiment), definida como a condição existencial na qual a cultura e o self estão ancorados. O autor, que se serve da etnografia como método de pesquisa, realiza seus estudos no campo dos rituais religiosos, buscando compreender a participação humana no mundo da cultura a partir da experiência do corpo.

Laplantine (2000) assinala que a fenomenologia influenciou e influencia, ainda, a etnografia. A abordagem fenomenológica, referenciada principalmente em

4 Vanguarda posbauschiana em referência à obra de Pina Bausch. 
Merleau-Ponty, permitiu aos etnógrafos compreenderem que "não existem fatos em estado puro aguardando que lhes sejam atribuídos significados [...] e que o sentido não é separado do sensível" (p. 101). Desse modo, Laplantine (2000) explica que a fenomenologia contribui para refinar o método etnográfico, pois a descrição fenomenológica fornece, sem dúvida, numa época de ceticismo crescente em relação às grandes explicações clássicas da objetividade, um certo número de instrumentos que auxiliam na observação dos eventos e fenômenos estudados. De modo semelhante, Thomas (2003) destaca que a fenomenologia contribui para que se entenda a etnografia como atividade que engaja a corporeidade do pesquisador e para que se compreenda o campo etnográfico como um espaço físico, social e imaginário que deve ser incorporado pelo pesquisador. Nesse sentido, a autora ressalta o potencial da fenomenologia e da etnografia para o desenvolvimento de estudos em dança.

Partindo dessas referências, todas as etapas de realização dessas investigações foram e são influenciadas pela minha experiência como intérprete em dança contemporânea. Tratam-se, então, de pesquisas realizadas por uma bailarina, sobre modos de se fazer dança, englobando aspectos como a formação de bailarinos e a criação e a interpretação de coreografias. São experiências que já compartilhei com outros intérpretes, trabalhando em colaboração com outros coreógrafos, e essas experiências influenciam tanto na definição das questões de pesquisa quanto nas minhas escolhas teóricas e metodológicas.

A etnografia possibilitou compreender diferentes aspectos da prática artística e da vida de coreógrafos e bailarinos que colaboraram nessas investigações, dentre os quais destaco:

a) aspectos culturais, relacionados à influência de referências culturais, sociais e políticas na obra dos coreógrafos escolhidas e suas consequências no trabalho realizado em colaboração com os bailarinos;

b) aspectos especificamente artísticos, ligados à criação, manutenção e reconstrução de obras coreográficas, visando compreender as relações estabelecidas entre bailarinos e coreógrafos ao longo desse processo;

c) aspectos ligados à formação de bailarinos, em particular aos processo de construção de corpos dançantes relacionados à participação na criação, manutenção e reconstrução de obras coreográficas.

Assim, utilizei uma abordagem etnográfica para compreender o sentido que essas práticas coreográficas têm para os bailarinos e coreógrafos. Esta abordagem permitiu também situá-las no contexto da produção atual em dança contemporânea, bem como possibilitou refletir sobre as relações entre tais práticas e os contextos culturais que as englobam.

Nos últimos anos, tenho também trabalhado com a autoetnografia para refletir sobre meu próprio trabalho como bailarina em duas obras - Bundaflor Bundamor ${ }^{5}$ e

5 Bundaflor Bundamor inspira-se, como não poderia deixar de ser, na bunda de cada um, mas também na bunda que habita o imaginário de todos. Concepção e coreografia de Eduardo Severino e Luciano Tavares, estreou em 2008. Na época, era dançado por Eduardo Severino, Luciano Tavares, eu, Dani Boff e Luciana Hoppe. Desde então, foi-se modificando, até chegar a sua versão mais conhecida, dançada por Eduardo Severino, Luciano Tavares e por mim. Já foi apresentado no Chile e no México e em 2013 fez parte do Projeto Circulação em Dois Atos - Prêmio Funarte Klauss Vianna de Dança 2012, circulando por cidades como Salvador, Recife, Rio Branco, Florianópolis, Pelotas e Caxias do Sul. 
Tempostepegoquedelícia ${ }^{6}$ - criadas em colaboração com Eduardo Severino e Luciano Tavares na Eduardo Severino Companhia de Dança7 (Dantas 2010, 2014). Tenho me dedicado a pensar em como essas coreografias fazem sentido para mim e para o público que as assiste.

De uma experiência como observadora participante, nos estudos etnográficos, passo para uma experiência de participante observadora, nos estudos autoetnográficos. Em outras palavras, as sensações, percepções, sentimentos e pensamentos decorrentes da minha presença como artista envolvida na criação das obras investigadas por mim mesma constituíram os principais dados a serem produzidos. Durante o período de ensaios, registrei muitas das minhas anotações em notas esparsas, juntamente com alguns diálogos informais ocorridos durante os ensaios. No entanto, muitas outras impressões, diálogos e situações foram ressurgindo durante a escrita dos artigos.

Numa etnografia, a observação é um dos principais modos de produção da informação. É um atividade que mobiliza o olhar. Laplantine (2002) explica que a observação participante supõe um esforço para "fazer ver": para além de ver, é necessário registrar a informação visual e, em seguida, transformar o olhar em linguagem escrita. Assim, a observação é uma atividade mediada, instrumentalizada e retrabalhada pela escrita.

Minha experiência com a autoetnografia mostrou que o exercício da escrita torna-se um dos principais modos de produção da informação, uma vez que o olhar do pesquisador confunde-se com o olhar do artista, é um olhar que, ao se voltar para o processo de criação, não separa o fazer artístico do fazer investigativo.No meu caso, a escrita foi efetivamente o que favoreceu um relativo distanciamento e uma certa compreensão das obras e de seus processos.

Do mesmo modo, a conjugação do olhar e da escrita, tanto o caso da etnografia como da autoetnografia, permite a emergência de temas que nutrem a elaboração de perspectivas teóricas. Assim, pude constatar que nesse tipo de pesquisa os conceitos oriundos da reflexão teórica são constantemente confrontados e enriquecidos pelas informações produzidas no trabalho de campo. Em consequência, os referenciais conceituais estão sendo sempre reavaliados. Como ressaltam Alvesson e Sköldberg (2001), as informações e dados empíricos são impregnados de teoria e as teorias se constituem através da observação de certos aspectos da realidade e da vida humanas.

Sendo assim, os estudos de Bundaflor Bundamor e Tempostepegoquedelícia, baseados na descrição das minhas sensações e impressões, levaram a uma reflexão sobre a exposição da intimidade do corpo nu em cena e a uma discussão sobre como essa exposição desestabiliza representações de gênero.

No estudo sobre Bundaflor Bundamor (Dantas), a descrição dos meus sentimentos em relação ao fato de expor as nádegas - ou melhor, a bunda - foram pre-

6 Tempostepegoquedelícia é um duo criado em 2011 por Eduardo Severino em colaboração comigo e com Luciano Tavares, que interpretamos a obra. Vestes hieráticas, homem e mulher portando falos feitos de enfeites natalinos, homem em tubinho e decote sexy, mulher vestida como um pivete, coletes de pele, cueca e calcinha vermelhas e corpos nus interrogam, com humor, a falocracia que marca as relações interpessoais na cultura brasileira, e que acaba encontrando reflexo nas criações artísticas. Já foi Já foi apresentado no Chile e no México e em 2013 também fez parte do Projeto Circulação em Dois Atos - Prêmio Funarte Klauss Vianna de Dança 2012.

7 A Eduardo Severino Companhia de Dança foi criada em 2001 por Eduardo Severino e Luciano Tavares, em Porto Alegre. Tem em seu repertório 15 obras e diversos prêmios, como o Açorianos de Dança e o Funarte Klauss Vianna de Dança. Desde 2005 integra o Projeto Usina das Artes/Prefeitura Municipal de Porto Alegre. Ver https://eduardoseverinociadedanca.wordpress.com/ 
ponderantes:

Em uma dessas cenas, parados de frente para o público, abaixamos a parte posterior do maiô (eu) ou da sunga (Eduardo e Luciano). Cruzamos os braços e viramos de costas para o público. Ao som de Não me diga adeus, de Aracy de Almeida, ficamos parados; não nos mexemos durante toda a música. [...] Este era um dos momentos mais íntimos do trabalho, embora houvesse outras cenas em que dançássemos com as bundas à mostra. No entanto, nenhuma outra situação essa sensação de exposição e intimidade, pois desvestir a bunda e virar de costas para o público é oferecer uma parte vulnerável do corpo, compartilhando algo que me é íntimo. Recordo que algumas vezes, em cena, pensava no que poderiam pensar os espectadores instantes antes de eu virar de costas; havia, pois, entre a ação de abaixar o maiô e de virar de costas, uma certa hesitação. Hesitação semelhante a que sinto ao escrever sobre minha experiência em dançar com a bunda à mostra, o que não deixa de ser uma outra maneira de me expor (2010, p. 10).

Já no estudo sobre Tempostepegoquedelícia (Dantas) acabei por ressaltar a interação com referenciais teóricos:

Tempostepegoquedelícia parece dissolver uma representação de gênero na outra: quem é mais feminino? A mulher de calção, camiseta larga e touca de lã? O homem de vestido justo e decote nas costas? Como explica Butler, "o corpo é um processo de materialização que se estabiliza ao longo do tempo para produzir o efeito de limite, fixidez e superfície que chamamos de matéria". A autora argumenta que as partes sexuadas do corpo são investidas de significado, pois a descrição do corpo é um enunciado performativo e a linguagem que parece simplesmente descrever o corpo, na verdade o constitui. Na cena final, em que os dois intérpretes rolam abraçados pelo chão, a nudez reenvia a uma possibilidade de igualdade ou contribui para marcar o feminino e o masculino? Essa ação é capaz de produzir um enunciado performativo que pode desestabilizar hierarquias - do feminino e do masculino, das partes do corpo que podem ou não ser mostradas - e ressignificar o corpo e suas partes? (2014, p. 211).

\section{Considerações}

Neste texto eu não tive a intenção de afirmar que a etnografia e autoetnografia sejam as alternativas metodológicas mais indicadas para a realização de pesquisas no campo dos estudos em dança. Pesquisadores brasileiros como Fernando Aleixo, Milton de Andrade, André Carreira, Silvia Davini, Narciso Telles ${ }^{8}$ (citados por Telles, 2012) e Ciane Fernandes (2015) tem advogado que a pesquisa em artes cênicas deve desenvolver abordagens metodológicas próprias, desestabilizando dicotomias como teoria e prática, corpo e mente, inteligível e sensível, acadêmico e artístico, racional e intuitivo.

Embora concordando com Fernandes (2015), quando a autora afirma ser necessário que as artes cênicas deixem de pensar que "[...] precisamos nos basear em áreas mais consolidadas para legitimar nossas pesquisas" (p. 76), penso que ainda seja pertinente examinar algumas experiências de pesquisas em dança que vem se servindo da etnografia e da auto-etnografia como ferramentas metodológicas. Em geral, muitas dessas pesquisas são radicalmente ancoradas no corpo e na experiência de

8 Narciso Telles organizou a publicação de um livro que tem se tornado referência na pesquisa em artes cênicas, contendo artigos desses pesquisadores (Telles, 2012). 
quem delas participa, interpelando também a corporeidade de seus interlocutores e leitores.

\section{Referências}

ALVESSON, Mats; SKÖLDBERG, Kaj. Reflexive Methodology: New Vistas for Qualitative Research. London: Sage, 2001.

ANDRADE, Mário. Danças dramáticas do Brasil. Belo Horizonte: Itatiaia, 1959.

BAKKA, Egil. Or Shortly They Would be Lost Forever: Documenting for Revival and Research. In BUCKLAND, T. J. (Org.). Dance in the Field: Theory, Methods and Issues in Dance Ethnography, London: MacMillan, 1999, p. 71-82.

BLUMENFELD-JONES, Donald. Dance as a Mode of Research Representation. Qualitative Inquiry, n. 1, p. 391-401, 1995.

BROWNING, Barbara. Samba: resistance in motion. Indianapolis: Indiana University Press, 1995.

CAMPOS, Flávio; RODRIGUES, Graziela Estela Fonseca. O Processo B.P.I. e suas especificidades epistemológicas. Revista Brasileira de Estudos da Presença, Porto Alegre, v. 5, n. 3, p. $490-506,2015$.

CASTRO, Cássia Navas Alves de. Entrevistar e escrever: procedimentos para palavras encarnadas na dança. Revista Brasileira de Estudos da Presença, Porto Alegre, v. 5, n. 3, p. 559-576, 2015.

CONTE, Richard. Qu'est-ce qu'une pratique? Æ Revue canadienne d'esthétique, Montreal, v. 5, 2000. Disponível em: http://www.uqtr.uquebec.ca/AE/Vol_5/Conte/Conte.htm. Acesso em: 15 jun. 2006.

CSORDAS, Thomas J. 1993. Somatic Modes of Attention. Cultural Anthropology, vol. 8 , no 1, p. 135-155.

CSORDAS, Thomas J. Introduction: the Body as Representation and Being-in-the -World. In CSORDAS, T. (Org.). Embodiment and experience. The existential ground of culture and self. Cambridge: Cambridge University Press, 1994. p. 1-24.

DANTAS, Mônica Fagundes. Dança, o enigma do movimento. Porto Alegre: Editor da Universidade/UFRGS, 1999.

De que são feitos os dançarinos de "aquilo..." : criação coreográfica e formação de intérpretes em dança contemporânea. Revista Movimento, Porto Alegre, v. 
11, n. 2, p. 31-57, maio/agosto 2005.

A pesquisa em dança não deve afastar o pesquisador da experiência da dança: reflexões sobre escolhas metodológicas no âmbito da pesquisa em dança. Revista da Fundarte, Montenegro n.13/14, p. 13-18, 2007.

Ce dont sont faits les corps anthropophages: la participation des danseurs à la mise en œuvre chorégraphique comme facteur de construction de corps dansants chez deux chorégraphes brésiliennes. Montreal, 2008. Tese (Doutorado) - Études et pratiques des arts. Université du Québec à Montréal.

Corpos nus e seminus na coreografia contemporânea: intimidade e exposição em Aquilo de que somos feitos e Bundaflor Bundamor. O percevejo online, Rio de Janeiro, v. 2, n.2, p. 1-14, 2010. Disponível em: http://www.seer.unirio.br/index.php/ opercevejoonline/article/view/1453 Acesso em: 20 de set. 2016.

Fenômenos identitários e a produção coreográfica atual. In Ana Carolina Mundim; Beatriz Cerbino; Cássia Navas. (Org.). Mapas e percursos, estudos de cena. Belo Horizonte: Abrace, 2014, p. 203-215.

DAVIDA, Dena. Kealiinohomoku's Legacy: Watching dance as cultural practice through the 'dance event framework'. In PONTBRIAND, Chantal (Org.). Danse: langage propre et métissage culturel. Montreal: Parachute, 2001, p.73-88.

Luna révélée : une étude ethnographique sur la signification d'un événement de « Nouvelle Danse » montréalaise. Montreal, 2006. Tese (Doutorado) - Études et pratiques des arts. Université du Québec à Montréal.

FELFÖLDI, László. Folk Dance Research in Hungary: Relations among Theory, Fieldwork and the Archive. In BUCKLAND, T. J. (Org.). Dance in the Field: Theory, Methods and Issues in Dance Ethnography, London: MacMillan, 1999, p. 55-70.

FERNANDES, Ciane. Pesquisa somático-performativa: sintonia, sensibilidade, integração. Art Research Journal, Natal, v. 1, n.2, p. 76-95, 2014

FORTIN, Sylvie. La recherche qualitative dans le studio de danse: une relation dialogique de corps à corps. Revue de l'association pour la recherche qualitative, n. 10, p. 75-85, 1994.

Enseignement de la danse dans une perspective féministe: trois études de cas. Recherches Qualitatives, n. 19, p. 23-39, 1999.

Apports possibles de l'ethnographie et de l'autoethnographie pur la recherche en pratique artistique. In: GOSSELIN, Pierre; LE COGUIEC, Eric (Org.). La recherche en création: pour une compréhension de la recherche en pratique artistique. 
Québec: Presses de l'Université du Québec, 2006. p. 97-109.

FORTIN, Sylvie, LONG, Warwick. Percebendo diferenças no ensino e na aprendizagem de técnicas de dança contemporânea. Revista Movimento, Porto Alegre, v. 11, n. 2, p 9-29, maio/agosto 2005.

FORTIN, Sylvie; GOSSELIN, P. Considerações metodológicas para a pesquisa em arte no meio acadêmico. Art Research Journal, Natal, v. 1, n.1, p. 1-17, 2014.

FROSCH, Joan D. Dance Ethnography: Tracing the Wave of Dance. In FRALEIGH, SONDRA; HANSTEIN, Penelope (Org.). Researching Dancing: Evolving Modes of Inquiry. Pittsburg: University of Pittsburgh Press, 1999, p. 249-280.

GIURCHESCU, Anca. 1999. Past and Present in Field Research: a Critical History of Personal Experience. In BUCKLAND, T. J. (Org.). Dance in the Field: Theory, Methods and Issues in Dance Ethnography, London: MacMillan, 1999, p.41-54

GORE, Georgiana. The beat goes on: transe, danse et tribalisme dans la culture rave. Nouvelles de danse, Bruxelas, n.34/35, p. 86-106, 1998.

GRAU, Andrée. L'acquisition de connaissances: l'apprentissage, par le corps, des liens de parenté chez les Tiwi d'Australie du Nord. Nouvelles de danse, Bruxelas, n. 34/35, p. $68-85,1998$.

GREEN, Jill. Choregraphing a Postmodern Turn: The Creative Process and Somatics. Impulse, n. 4, p. 267-275, 1996.

HANSTEIN, Penelope. From Idea to Research Proposal: Balancing the Systematic and Serendipitous. In: FRALEIGH, SONDRA; HANSTEIN, Penelope (Org.). Researching Dancing: Evolving Modes of Inquiry. Pittsburg: University of Pittsburgh Press, 1999, p. 62-88.

KAEPPLER, Adrianne L. Structured movement system in Tonga. In SPENCER, P (Org.). Society and the Dance. Cambridge: Cambridge University Press, 1985.

KEALIINOHOMOKU, Joann W. A Comparative Study of Dance as a Constellation of Motor Behaviors among African and United States Negroes. Reflections and Perspectives on Two Anthropological Studies of Dance. Congress On Research in Dance, n. 7, p. 1-179, 1976.

Une anthropologue regarde le ballet classique comme une forme de danse ethnique. Nouvelles de danse, n. 34/35, p. 47-67, 1998.

Uma antropóloga olha o Ballet Clássico como uma forma de dança étnica. In CAMARGO, Giselle. (Org.). Florianópolis: Insular, 2013, p. 123-142. 
KOUTSUBA, Maria. 1999. Outsider and Insider World, or Dance Ethnography at Home. In BUCKLAND, T. J. (Org.). Dance in the Field: Theory, Methods and Issues in Dance Ethnography, London: MacMillan, 1999, p.186-189.

LANCRI, Jean. Modestas proposições sobre as condições de uma pesquisa em artes plásticas na universidade. In: BRITTES, Blanca; TESSLER, Elida (Org.). O meio como ponto zero: metodologia da pesquisa em artes plásticas, Porto Alegre: Editora da Universidade/ UFRGS, 2002, p. 17-33.

LAPLANTINE, François. La description ethnographique. Paris: Nathan Université, 2000.

LEPECKI, Andre. Par le biais de la présence. Nouvelles de danse, Bruxelas, n. 36/37, p. 183-193, 1998.

MERLEAU-PONTY, Maurice. Fenomenologia da Percepção. Rio de Janeiro: Freitas Bastos, 1971.

MARCUS, George; FISCHER, Michael. Anthropology as Cultural Critique: An Experimental Movement in Human Sciences. Chicago: University of Chicago Press, 1986.

MARCUS, George. Au-delà de Malinowski et après Writing Culture: à propos du futur de l'anthropologie culturelle et du malaise de l'ethnographie. Ethnographiques.org, Paris, n. 1, 2002. Disponível em: http://www.ethnographiques.org/2002/Marcus.html Acesso em: 4 jun. 2006.

NOVACK, Cynthia. Sharing the dance: contact improvisation and American culture. Madison: The University of Wiscosin Press, 1990.

PATTON, Michel Q. Qualitative Research and Evaluation Methods. Thousand Oaks: Sage Publications, 2002.

PINTO, Isabel. História do teatro e performance: a insurreição do arquivo como método. Revista Brasileira de Estudos da Presença, Porto Alegre, v. 5, n. 3, p. 507-532, 2015.

RODRIGUES, Graziela. Bailarino, Pesquisador, Interpréte: Processo de Formação. Rio de Janeiro: Funarte, 1997.

SANTOS, Eluza Maria.The Dancing Voice of Culture: An Ethnography of Contemporary Dance in Vitória, Brazil. 1999. 234 f. Tese (Doutorado). Denton: Texas Woman's University, 1999.

SKLAR, Deidre. On Dance Ethnography. Dance Research Journal, n. 23, p. 6-9, 1991. 
STINSON, Suzan W. A Place Called Dance in School : Reflecting on What the Students Say. Impulse, n. 1, p. 90-114, 1993.

TELLES, Narciso. (Org.). Pesquisa em Artes Cênicas: Textos e Temas. Rio de Janeiro: E-papers, 2012.

THOMAS, Helen. The Body, Dance and Cultural Theory. Hampshire: Plagrave Macmillan, 2003.

TURNER, Bryan S.; WAINWRIGHT, Steven P. Corps de Ballet: The Case of the Injured Ballet Dancer. Sociology of Health and Illness. vol. 25, n. 4, p. 269-288, 2003.

WULFF, Helena. Ballet across borders : career and culture in the world of dancers. New York: Berg, 1998.

Recebido em: 30/09/2016

Aprovado em: 02/112016 